\title{
BMJ Open Theoretical constructs of smoking cessation among current tobacco smokers in India: a secondary analysis of Global Adult Tobacco Survey-2 (2016-2017)
}

\author{
Garima Bhatt (D) , Sonu Goel, Kathirvel Soundappan (1) , Rajbir Kaur (D)
}

To cite: Bhatt G, Goel S,

Soundappan K, et al. Theoretical constructs of smoking cessation among current tobacco smokers in India: a secondary analysis of Global Adult Tobacco Survey-2 (2016-2017). BMJ Open 2022;12:e050916. doi:10.1136/ bmjopen-2021-050916

- Prepublication history and additional supplemental material for this paper are available online. To view these files, please visit the journal online (http://dx.doi.org/10.1136/ bmjopen-2021-050916).

Received 09 March 2021 Accepted 16 December 2021

Check for updates

(c) Author(s) (or their employer(s)) 2022. Re-use permitted under CC BY-NC. No commercial re-use. See rights and permissions. Published by BMJ.

Department of Community Medicine and School of Public Health, Post Graduate Institute of Medical Education and Research (PGIMER), Chandigarh, India

Correspondence to

Dr Sonu Goel;

sonugoel007@gmail.com

\section{ABSTRACT}

Background Quitting tobacco smoking is a complex process, and the transtheoretical model describes the various stages of behaviour change that smokers experience to stop smoking. Predictors of intention to quit and stage of behavioural change could assist policymakers in establishing tailor-made strategies to offer support.

Objective In the current study, we analysed the determinants of cessation among 9499 current smokers of India recorded during the second Global Adult Tobacco Survey (2016-2017).

Methods Bivariate analysis, multivariate analysis (binary logistic regression was performed for past quit attempts and intention to quit smoking in the future; multinomial logistic regression to understand predictors of various stages of change determining cessation behaviour of current smokers) was undertaken.

Results The majority of the smokers was men (91.0\%), in $25-44$ years age group, $(42.3 \%)$, daily wagers $(37.4 \%)$ and resided in the rural area $(73.3 \%)$, with bidi being the most commonly smoked product ( $72 \%$ ). Nearly $72 \%$ tried to quit without any assistance with $36.6 \%$ (precontemplation), $27 \%$ (contemplation), $28 \%$ (preparation (or action)) and $8.1 \%$ in (relapse) stage. Men ((1.049); $95 \% \mathrm{Cl} 1.047$ to $1.051)$, the primary $(1.192 ; 95 \% \mathrm{Cl} 1.190$ to 1.193$)$ as well as higher education, being married $(1.231 ; 95 \% \mathrm{Cl} 1.229$ to 1.234 ) and urban residence $(1.167 ; 95 \% \mathrm{Cl} 1.1 .65$ to 1.168) were found to be associated with higher prevalence of previous quit attempts. The regression modelling found out that intent to quit reduced with increasing age and was similarly prevalent with any level of education.

Conclusion Understanding stages of behavioural change could assist the stakeholders in developing individualised interventions along with the development of intensive cessation protocols in clinical and public health settings.

\section{BACKGROUND}

Smoking cessation at any age is associated with substantial health and economic benefits $^{1}$ along with the addition of considerable longevity. ${ }^{2}$ In comparison to non-smokers, smokers who start smoking early in adulthood
Strengths and limitations of this study

This analysis provides an understanding of the stage of behavioural change among current smokers of India.

- It addresses the key determinants of quit attempts and intention to quit that would support the design of individual and population-based tobacco cessation programmes in India.

- The article provides specific recommendations for policy and practice for increasing awareness about cessation services at various points of patient contact.

- The study design does not permit us to establish a temporal relationship, and the responses collected during the survey are susceptible to recall bias.

- The predictors of quit attempt and intention to quit may vary for various forms of tobacco consumption which was not included in this analysis.

lose a decade of life expectancy. Smoking cessation, especially before the age of 40 , leads to a substantial decrease in mortality risk. ${ }^{3}$ Due to nicotine dependence, the smoker is required to make multiple quit attempts to quit finally. ${ }^{4} \mathrm{~A}$ prospective cohort study of smokers estimated that it might take 30 or more quit attempts before quitting permanently. ${ }^{5}$ Apart from this, evidence suggests a varied number of quit attempts ranging from 8 to 10 (The American Cancer Society), ${ }^{6}$ 12-14 (Australian Cancer Council), ${ }^{7}$ 8-11 (The Centers for Disease Control and Prevention $)^{8}$ before quitting forever.

Quitting tobacco smoking is a complex process. ${ }^{9}$ The transtheoretical behavioural change model (TTM) describes the process of change that smokers experience to be able to stop smoking. As per the TTM, the smoker evolves through pre-contemplation, contemplation, preparation, action, maintenance 
and termination stages in the smoking cessation. ${ }^{10} \mathrm{~A}$ key element in achieving 'quit status' is the intention to quit smoking. ${ }^{11}$ This element before cessation has been stated as a determinant of whether the smoker would engage in a cessation programme, attempt to quit smoking and succeed in quitting. During the preparatory stage, the intent to quit may be higher than the latter, but it is not easy to demonstrate behavioural change. ${ }^{12}{ }^{13}$ Thus, it is crucial to analyse the factors influencing the intention to quit smoking in order to evaluate the diverse underlying contextual factors that influence a smoker's intention to quit smoking.

Global Adult Tobacco Survey (GATS), round-2 conducted in India in the year 2016-2017 recorded that almost two in five $(38.5 \%)$ adult smokers had attempted to quit smoking tobacco in the last 12 months prior to the survey. However, the proportion of smokers who made a quit attempt during GATS-1 (2010) and GATS-2 (2017) remained similar $(38.4 \%$ vs $38.5 \%)$. Further, nearly half of the cigarette $(47.4 \%)$ and bidi smokers $(48.7 \%)$ who made a quit attempt in the past 12 months were able to maintain a quit status for less than a month. ${ }^{14}$ However, the proportion of current smokers interested or planning to quit smoking increased from $46.6 \%$ (GATS-1) to $55.4 \%$ (GATS-2). ${ }^{14}$

India is a signatory to WHO's-Framework Convention on Tobacco Control (WHO-FCTC) and has been implementing Article 14 of WHO-FCTC concerning tobacco dependence and cessation. ${ }^{15}$ Further, the Government of India (GoI) launched National Tobacco Control Programme in 2007-2008 with one of the key objective of helping people quit tobacco use in conformance to Article 14 of WHO-FCTC. ${ }^{16}$ The GoI established Tobacco Cessation Centers (in 2002) at district hospitals. ${ }^{17}$ Further, m-cessation (December, 2015) and national tobacco quitline services were launched in 2016 and further expanded to satellite centres in $2018^{18}{ }^{19}$ to support tobacco users for quitting.

Understanding the sociodemographic variables and other factors in facilitating or restraining quit behaviour of tobacco users is essential for designing and implementing a focused tobacco control intervention. Furthermore, awareness of these factors may also promote tobacco cessation initiatives to establish a staged progression of smoking cessation. A data analysis of GATS-1 (2010),from India, demonstrated significant association of socio-demographic characteristics with quit attempts indicating the need to re-examine their effect on cessation. ${ }^{20}$ Another study conducted among Italian adults reported an association of successful quit attempts with higher education level and young age. ${ }^{21}$ Further, it is important to understand the factors that may influence different tobacco smokers by their personal characteristics (gender, age, caste, education and occupation) in order to optimise and strategise effective cessation campaigns. This understanding is solicited for tailoring the content of the message as per aforementioned classification so as to increase the message's relevance and ability to persuade. ${ }^{22}$
Evidence states that lower socioeconomic status (SES) is predictive of a lower probability of quit intention, quit attempts and successful quitting. A study conducted among Italian smokers found an association of successful recent quit attempts with higher educational level, absence of economic difficulties and younger age. ${ }^{21}$ An analysis of data from a population-based prospective study from Switzerland concluded that the determinants of behavioural change vary according to the smoking status. ${ }^{23}$ Besides, relapse often occurs even after multiple quitting attempts. Therefore, cessation interventions that support abstinence during this phase are important. ${ }^{24}$ There is a limited evidence from Low Middle Income Countries (LMICs) regarding the association between smoking cessation behaviour and SES. ${ }^{25}$

Determining the factors that influence quit intentions opens the door to developing effective policies and programmes to help Indian smokers quit. In smoking addiction, TTM measurement tools have a potential for evaluation of smoking cessation and planning quitbehaviour. TTM is a significant tool for smoking cessation with its ability to use different models of behaviour changes. ${ }^{26}$ Further, literature suggests that research on the predictors of the transition from preparation to action stage is warranted, which is largely missing in Indian population despite leading the tobacco use statistics globally $^{27}$ Therefore, in the current study, we undertook the secondary data analysis of GATS-2 to analyse the determinants of smoking cessation and intent to quit smoking among current tobacco smokers of India.

\section{METHODS}

\section{Study settings}

The nationwide representative survey of GATS (round 2) was carried out in the Indian sub continent during years $2016-2017^{14}$ covering a population of 1029 million (Census 2011). ${ }^{28}$

\section{Study design and data sources}

This study is secondary data analysis of GATS-2, India, 2016-2017 which is being conducted under the Global Tobacco Surveillance System. ${ }^{29}$ GATS is a nationwide cross-sectional household survey, which uses standardised methodology for monitoring tobacco use as well as tracking changes in key measures of tobacco control among adults aged 15 or above. ${ }^{30}$ The GATS- 2 out in 2016-2017 using a standardised methodology. Survey was a project of the Ministry of Health and Family Welfare, GoI and it designated Tata Institute of Social Sciences, Mumbai as the nodal implementing agency for the survey. The data collection fieldwork was conducted was carried out in all 30 states including Union Territories (Chandigarh and Puducherry) between August 2016 and February 2017 with a sample of 84047 households (30821 from urban areas and 53226 from rural areas) The survey used probability proportional to size sampling technique, with adoption of three stage sampling design 
Table 1 Distribution of sociodemographic and tobacco smoking-related attributes among current tobacco smokers in India, GATS 2016-2017

\begin{tabular}{|c|c|c|}
\hline Characteristic & Category & n (\%) \\
\hline Total & & 9499 \\
\hline \multirow[t]{4}{*}{ Age in years } & $15-24$ & $661(8.4)$ \\
\hline & $25-44$ & $4552(42.3)$ \\
\hline & $45-64$ & $3304(37.0)$ \\
\hline & 65 and above & $982(12.2)$ \\
\hline \multirow[t]{2}{*}{ Sex } & Male & $8434(91.0)$ \\
\hline & Female & $1065(9.0)$ \\
\hline \multirow[t]{4}{*}{ Education $(n=9495)^{\star}$} & No formal schooling & $2754(35.3)$ \\
\hline & Up to primary & $2909(28.8)$ \\
\hline & Up to secondary & $3314(31.1)$ \\
\hline & Graduation and above & $518(4.8)$ \\
\hline \multirow[t]{5}{*}{ Occupation $(n=9496)^{\star}$} & Daily wager & $3220(37.4)$ \\
\hline & Self employed & $3148(34.1)$ \\
\hline & Retired/unemployed/homemaker & $1603(14.9)$ \\
\hline & Govt. and Non-govt. employee & $1351(12.0)$ \\
\hline & Student & $174(1.5)$ \\
\hline \multirow[t]{3}{*}{ Marital status } & Married & $8133(84.2)$ \\
\hline & Single & $882(10.2)$ \\
\hline & Separated/divorced/widowed & $484(5.6)$ \\
\hline \multirow[t]{3}{*}{ Caste $(n-9437)^{\star}$} & Scheduled caste/scheduled tribe & $4235(33.6)$ \\
\hline & Other backward class & $2895(42.3)$ \\
\hline & General (none of above) & $2307(24.2)$ \\
\hline \multirow[t]{2}{*}{ Area of residence } & Rural & $6980(73.3)$ \\
\hline & Urban & $2519(26.7)$ \\
\hline \multirow[t]{3}{*}{ Age of initiation of tobacco smoking $(n=8128) \dagger$} & $<15$ years & $707(8.1)$ \\
\hline & 15-25years & $5130(60.4)$ \\
\hline & $>25$ years & $2291(31.5)$ \\
\hline \multirow[t]{2}{*}{ Smoking frequency } & Daily & $7647(80.5)$ \\
\hline & Less than daily & $1852(19.4)$ \\
\hline \multirow[t]{6}{*}{ Type of smoking tobacco used $(n=11936) \ddagger$} & Bidi & $6070(72.3)$ \\
\hline & Cigarette & $3338(32.6)$ \\
\hline & Rolled tobacco & $1297(7.9)$ \\
\hline & Hukkah & $699(6.6)$ \\
\hline & Cheroot & $329(2.9)$ \\
\hline & Others & $203(1.3)$ \\
\hline \multirow[t]{2}{*}{ Quit attempt within past 12 months } & No & $6296(63.7)$ \\
\hline & Yes & $3203(36.3)$ \\
\hline \multirow[t]{2}{*}{ Intent to quit tobacco in future } & Interested in quitting & $5382(55.3)$ \\
\hline & Not interested in quitting & $4117(44.7)$ \\
\hline \multirow{3}{*}{$\begin{array}{l}\text { Source of information about harms or quitting } \\
\text { tobacco smoking }\end{array}$} & Haven't noticed & $2331(25.0)$ \\
\hline & $\leq 3$ sources & $4201(42.5)$ \\
\hline & $>3$ sources & $2967(32.5)$ \\
\hline
\end{tabular}

Continued 


\begin{tabular}{|c|c|c|}
\hline Characteristic & Category & n (\%) \\
\hline \multirow{3}{*}{$\begin{array}{l}\text { Noticed advertisements or signs promoting } \\
\text { tobacco smoking }\end{array}$} & None & $7495(76.4)$ \\
\hline & $\leq 2$ sources & $1080(11.4)$ \\
\hline & $<2$ sources & 924 (12.2) \\
\hline \multirow[t]{2}{*}{ Noticed any type of cigarette promotion } & No & $8736(91.9)$ \\
\hline & Yes & $763(8.1)$ \\
\hline \multirow[t]{2}{*}{ Noticed any type of bidi promotion } & No & $8580(89.0)$ \\
\hline & Yes & $919(11.0)$ \\
\hline \multirow{3}{*}{$\begin{array}{l}\text { Has smoking already done harm to your body } \\
(n=9488)^{\star}\end{array}$} & No & $4133(47.9)$ \\
\hline & Yes & $4933(49.3)$ \\
\hline & Don't know & $422(2.8)$ \\
\hline \multirow{3}{*}{$\begin{array}{l}\text { Whether smoking tobacco causes serious illness } \\
(n=9494)^{\star}\end{array}$} & Yes & $8632(91.3)$ \\
\hline & No & $684(6.9)$ \\
\hline & Don't know & $178(1.8)$ \\
\hline \multirow{3}{*}{$\begin{array}{l}\text { Whether smoking tobacco causes no, one or } \\
\text { multiple illnesses }\end{array}$} & No illness & $361(3.7)$ \\
\hline & Up to 3 illnesses & $3400(38.0)$ \\
\hline & $>3$ illnesses & $5738(58.3)$ \\
\hline \multirow{4}{*}{$\begin{array}{l}\text { Cessation behaviour based on stages of change } \\
\text { model }\end{array}$} & Pre-contemplation & $3446(36.6)$ \\
\hline & Contemplation & $2850(27.0)$ \\
\hline & Preparation/action! & $2532(28.2)$ \\
\hline & Relapse & $671(8.1)$ \\
\hline
\end{tabular}

(All percentage is weighted).

*Some participants refused to answer to that particular question, reflecting as changed denominator for analysis. †Information not available for all current less than daily tobacco smokers. $\ddagger$ Multiple responses per participant ( $\mathrm{n}=$ frequency of responses and not respondents).

GATS, Global Adult Tobacco Survey.

for rural areas (Villages-Households-Respondent) and a four stage was for urban areas (Wards- Census Enumeration Block- Households- Respondent). ${ }^{14}$

\section{Sample size}

Out of the total sample, we extracted the sample of 9499 respondents who were current tobacco smokers (daily and less than daily).

\section{Patient and public involvement}

No patient involved

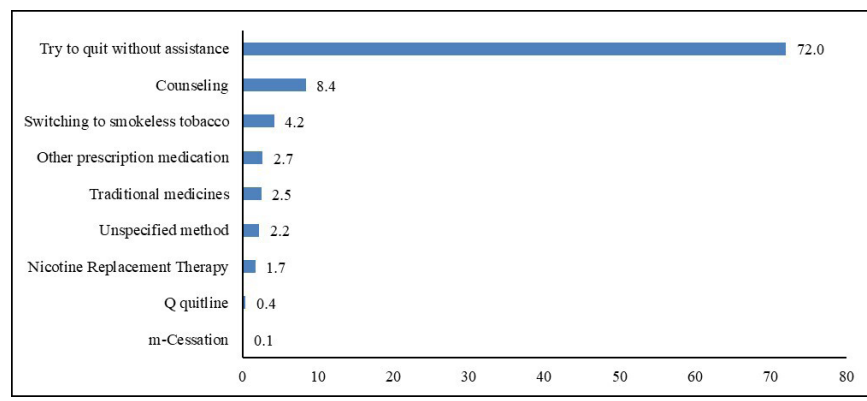

Figure 1 Cessation methods used by the current smokers who attempted to quit smoking in last 12 months, GATS 2016-2017. GATS, Global Adult Tobacco Survey.

\section{Operational definitions}

The following operational definitions were used in GATS for variables under the study:

- Current tobacco smoker: An individual who currently smokes any tobacco product, either daily or occasionally.

- A quit attempt in the survey was defined as current tobacco smokers who tried to quit during the past 12 months and former tobacco smokers and smokeless tobacco users who have been abstinent for $<12$ months. In this analysis, we included the former one.

- Intention in quitting smoking in the future was defined as current tobacco smokers planning or thinking about quitting smoking within the next month, 12 months or someday. ${ }^{14}$

- Stage of Change: Based on the tobacco smoking cessation behaviour, the current tobacco smokers were classified into following stages of change.

Precontemplation: The current tobacco smokers who neither made a quit attempt in the past nor intend to quit in the future.

Contemplation: The current tobacco smokers who did not make a quit attempt in past but intend to do so in future. 


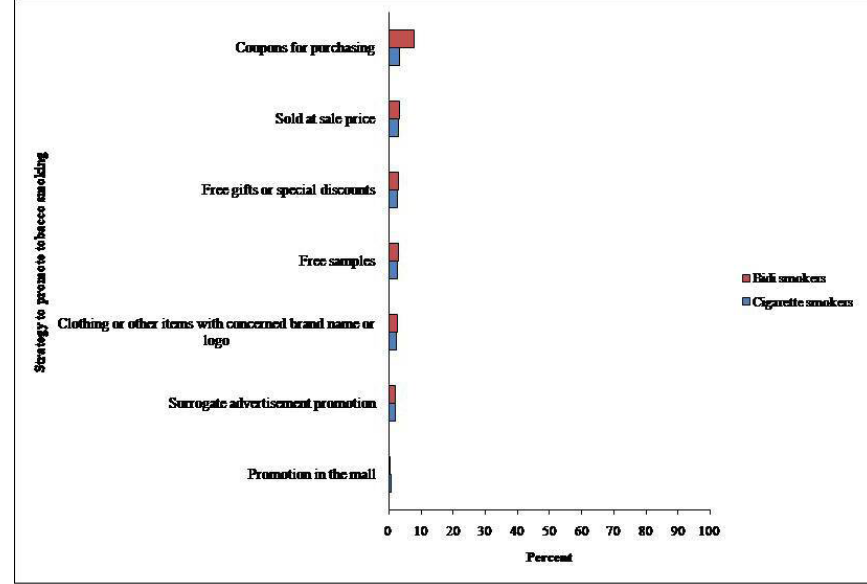

Figure 2 Distribution of promotional strategies encouraging smoking noticed by the current tobacco smokers in past 30 days, GATS 2016-2017. GATS, Global Adult Tobacco Survey.

Preparation (or action!): The current tobacco smokers who made a quit attempt in the past and intend to quit in the future (apparently because their past quit attempt could not yield success).

Relapse: The current tobacco smokers who made an unsuccessful quit attempt in the past do not intend to quit in the future.

\section{Study variables}

Outcome variables included past quit attempts and intention to quit tobacco smoking in future. The exposure variables included sociodemographic characteristics, smoking history and pattern, exposure to media advertisements for and against tobacco smoking, and knowledge about the health effects of tobacco smoking. The questions used for analysis along with codes are added to online supplemental file 1 .

\section{Data analysis}

We performed univariate analysis (frequency distribution), bivariate analysis $\left(\chi^{2}\right)$, and multivariate

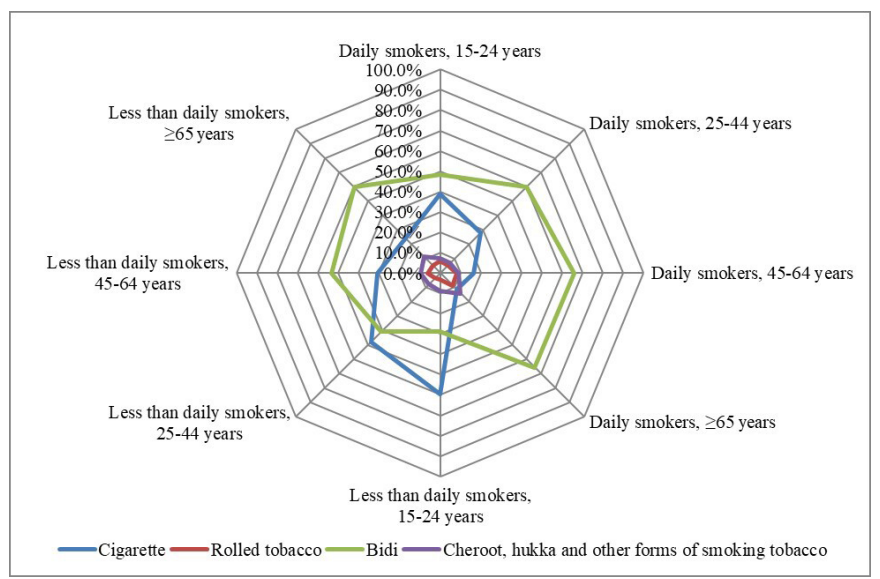

Figure 3 Agewise distribution of smoking tobacco product use among current daily and less than daily tobacco smokers, GATS 2016-2017. GATS, Global Adult Tobacco Survey. analysis (binary logistic regression for outcome variables mentioned above; and; multinomial logistic regression to understand predictors of various stages of change determining cessation behaviour of current tobacco smokers. The analysis was performed in SPSS software, V.16 (SPSS, released 2007) (with $\mathrm{p}<0.05$ ).

\section{RESULTS}

A total of 9499 current tobacco smokers were identified. The sociodemographic distribution of current smokers is presented in table 1. Sixty-three per cent of the current smokers had made a quit attempt within past 12 months from the survey. Around $44 \%$ of participants had no intention to quit tobacco smoking in the near future. More than $90 \%$ tobacco smokers were aware about serious illnesses caused by smoking tobacco. Further, 11\% reported to have witnessed one or other type of promotion of bidi smoking. Based on the cessation behaviour of current smokers, they were classified into four groups using the stages of change model. ${ }^{10}$ The analysis revealed that $36.6 \%$ of current tobacco smokers were in the precontemplation stage (table 1 ).

Nearly $72 \%$ of current tobacco smokers tried to quit without any assistance, whereas counselling was sought by $8.4 \%$ of tobacco smokers. Further, $4.2 \%$ switched to smokeless tobacco as well. Nicotine replacement was sought by an even lesser proportion (1.7\%) (figure 1).

Maximum promotion was noticed for bidi products in the form of coupons for purchasing $(7.8 \%)$, followed by sale at low price $(3.4 \%)$ or as free gifts $(3.2 \%)$ in comparison to cigarette promotion. However, the surrogate advertisement promotion was more for cigarettes $(2.2 \%)$ than bidis (2\%) (figure 2).

The age-related distribution of various tobacco smoking products was assessed for current tobacco smokers based on smoking frequency. Daily bidi smoking was practised by 45 years and above age group. This was represented using spider diagram to highlight the age wise difference in daily and non-daily use of smoking tobacco in various forms (figure 3).

The males, primary as well as higher education (graduation and above), being employed (or retired), married, higher caste and urban residence were found to be associated with higher prevalence of previous quit attempts among current smokers. Further, exposure to regular smoking during early adulthood, perception and awareness about ill effects of smoking on body, and smoking being able to cause a multitude of health effects was also associated with increased quit attempts (table 2).

\section{Factors affecting intent to quit tobacco in near future}

The regression modelling revealed that intent to quit reduced with increasing age and was similarly prevalent with any level of education. Having an occupation with monetary outcomes (ie, except being student), being married, initiation after the age of 25 years, experience of ill health effect due to smoking, perception about 
Table 2 Factors affecting tobacco quitting attempts within past 12 months among the current smokerss, GATS 2016-2017

\begin{tabular}{|c|c|c|c|}
\hline \multirow[b]{2}{*}{ Factor } & \multicolumn{3}{|l|}{ Quit attempt } \\
\hline & $\%(n=3203)$ & Unadjusted PR $(95 \% \mathrm{Cl})$ & Adjusted PR $(95 \% \mathrm{Cl})$ \\
\hline \multicolumn{4}{|l|}{ Age in years } \\
\hline $15-24$ & 34.4 & $1.033(1.031$ to 1.035$)$ & 1.391 (1.387 to 1.395$)$ \\
\hline $25-44$ & 37.9 & $1.202(1.200$ to 1.203$)$ & $1.082(1.080$ to 1.083$)$ \\
\hline $45-64$ & 35.9 & 1.106 (1.104 to 1.107$)$ & 0.941 (0.939 to 0.942$)$ \\
\hline 65 and above & 33.7 & Ref & \\
\hline \multicolumn{4}{|l|}{ Sex } \\
\hline Male & 36.9 & 1.297 (1.295 to 1.299$)$ & 1.049 (1.047 to 1.051$)$ \\
\hline Female & 31.0 & Ref & \\
\hline \multicolumn{4}{|l|}{ Education $(n=9495)^{*}$} \\
\hline Up to primary & 39.8 & 1.377 (1.375 to 1.378$)$ & $1.192(1.190$ to 1.193$)$ \\
\hline Graduation and above & 37.7 & 1.260 (1.258 to 1.263$)$ & 1.115 (1.112 to 1.118$)$ \\
\hline Up to secondary & 37.3 & $1.239(1.238$ to 1.241$)$ & 0.993 (0.992 to 0.994$)$ \\
\hline No formal schooling & 32.5 & Ref & \\
\hline \multicolumn{4}{|l|}{ Occupation $(n=9496)^{\star}$} \\
\hline Govt. and non-govt. employee & 41.0 & 2.076 (2.068 to 2.084$)$ & $1.269(1.262$ to 1.276$)$ \\
\hline Self employed & 38.7 & 1.885 (1.878 to 1.892$)$ & $1.292(1.285$ to 1.299$)$ \\
\hline Daily wager & 34.7 & 1.511 (1.586 to 1.597$)$ & 1.097 (1.091 to 1.104$)$ \\
\hline Retired/unemployed/homemaker & 32.7 & $1.450(1.445$ to 1.456$)$ & $1.113(1.107$ to 1.119$)$ \\
\hline Student & 25.1 & Ref & \\
\hline \multicolumn{4}{|l|}{ Marital status } \\
\hline Married & 37.2 & 1.335 (1.332 to 1.337$)$ & $1.231(1.229$ to 1.234$)$ \\
\hline Single & 32.0 & 1.059 (1.056 to 1.061$)$ & 0.789 ( 0.787 to 0.791$)$ \\
\hline Separated/divorced/widowed & 30.8 & Ref & \\
\hline \multicolumn{4}{|l|}{ Caste $(n=9437)^{\star}$} \\
\hline Other backward class & 41.0 & 1.461 (1.460 to 1.462$)$ & $1.461(1.460$ to 1.462$)$ \\
\hline General & 33.5 & $1.062(1.061$ to 1.063$)$ & 1.062 (1.061 to 1.063$)$ \\
\hline Scheduled caste/scheduled tribe & 32.2 & Ref & \\
\hline \multicolumn{4}{|l|}{ Area of residence } \\
\hline Urban & 39.3 & 1.187 (1.186 to 1.188$)$ & 1.167 (1.165 to 1.168$)$ \\
\hline Rural & 35.3 & Ref & \\
\hline \multicolumn{4}{|l|}{ Smoking frequency } \\
\hline Less than daily smoking & 41.4 & $1.303(1.301$ to 1.304$)$ & $1.303(1.301$ to 1.304$)$ \\
\hline Daily smoking & 35.1 & Ref & \\
\hline \multicolumn{4}{|c|}{ Age of initiation of regular smoking $(n=8128) \dagger$} \\
\hline$<15$ years & 37.3 & 1.090 (1.089 to 1.092$)$ & 1.095 (1.093 to 1.097$)$ \\
\hline$>25$ years & 36.9 & $1.069(1.068$ to 1.070$)$ & 1.109 (1.108 to 1.110$)$ \\
\hline 15-25years & 35.3 & Ref & \\
\hline \multicolumn{4}{|c|}{ Has smoking already done harm to your body } \\
\hline Yes & 39.8 & 2.428 (2.421 to 2.435$)$ & 2.322 (2.314 to 2.330$)$ \\
\hline No & 33.7 & $1.867(1.862$ to 1.873$)$ & $1.808(1.802$ to 1.815$)$ \\
\hline Don't know & 21.4 & Ref & \\
\hline \multicolumn{4}{|c|}{ Whether smoking tobacco causes serious illness } \\
\hline Yes & 37.1 & 3.155 (3.142 to 3.168$)$ & 2.121 (2.111 to 2.131$)$ \\
\hline No & 31.2 & 2.424 (2.413 to 2.434$)$ & $1.947(1.937$ to 1.957$)$ \\
\hline
\end{tabular}




\begin{tabular}{|c|c|c|c|}
\hline \multirow[b]{2}{*}{ Factor } & \multicolumn{3}{|l|}{ Quit attempt } \\
\hline & $\%(n=3203)$ & Unadjusted PR $(95 \% \mathrm{Cl})$ & Adjusted PR $(95 \% \mathrm{Cl})$ \\
\hline Don't know & 15.8 & Ref & \\
\hline$>3$ illnesses & 38.4 & $1.830(1.826$ to 1.834$)$ & $1.435(1.431$ to 1.439$)$ \\
\hline Up to 3 illnesses & 34.3 & $1.530(1.527$ to 1.534$)$ & $1.244(1.240$ to 1.248$)$ \\
\hline
\end{tabular}

(All percentage is weighted).

*Some participants refused to answer to that particular question, reflecting as changed denominator for analysis. †Information not available for all current less than daily tobacco smokers.

GATS, Global Adult Tobacco Survey; PR, prevalence ratio.

smoking being able to cause serious and multitude of illnesses and those who recently noticed more than two advertisements about tobacco products was associated with higher odds of intention to quit in future (table 3).

The sociodemographic profile of current smokers and their smoking related attributes were tested to find out predictors of being in any of the stages of TTM. ${ }^{10}$ Younger age, female sex, non-exposure to advertisements promoting smoking,werecommon predictors of being in contemplation and preparation stage. Further, experience of ill health effects because of smoking was a common predictor to contemplation, preparation and relapse stage.

The perception about tobacco being able to cause serious health effects (contemplation); education up to primary level, daily wager, other backward class caste, being married (preparation); lack of formal education, self-employment, any caste other than general, initiation of tobacco use at age less than 25 years, noticing information encouraging tobacco use as well as quitting, perception about tobacco not being able to cause serious health effects (relapse) were additional predictors (table 4).

\section{DISCUSSION}

The focus of this paper was to look for the determinants of two major aspects of tobacco smoking cessationquit attempts and intent to quit as they can help us in understanding smokers' attitude and behaviour towards smoking cessation. We utilised the TTM for a cyclic representation of factors influencing behavioural change of a smoker which will facilitate tailored heath promotion strategies that are individualised and easily adapted. The purpose of TTM is to delineate smoker's behaviour under the five stages and describe how smokers move dynamically through them. The TTM model used in the study has aptly proved that smokers not only perceive more benefits as they move in later stages but are also being influenced by a different set of determinants for smoking cessation. This view has been supported by other studies on physical activity, ${ }^{31}$ sedentary behaviour, ${ }^{32}$ nutritional interventions, ${ }^{33}$ etc. The TTM's ability to customise its constructs to an individual's readiness to initiate cessation behaviour is a major strength, making individually based interventions applicable at the population level. The TTM is flexible enough to be employed by almost any sort of practitioner or researcher, which adds to the possibility of a population-based intervention strategy. The TTM can combine clinical and public health strategies to increase the likelihood of successful health behavioural change. ${ }^{34}$

Out of the current tobacco smokers who made a quit attempt in past, majority reported $(72 \%)$ to have attempted to quit without any assistance. This could be due to various reasons such as lack of awareness among users about the available treatment options (pharmacotherapy and nicotine replacement therapy, quitlines and mCessation), concerns about their safety and perceiving that unassisted is a better choice ${ }^{35} 36$ The lower odds of quit attempt among the older age groups in the study may be attributed to higher nicotine addiction level, ${ }^{37}$ beliefs about quitting, believing that 'the damage had been done' so they see no point in attempting to quit later in life,${ }^{38}$ beliefs of healthcare providers (HCPs) reluctance to give cessation advice or to provide medication, type, location and visibility of smoking cessation services, ${ }^{39} 40$ reluctance to use telephone or online support such as m-cessation. ${ }^{41}$ Only after they contract some illness due to smoking, they think and perhaps attempt to quit (or reduce) smoking, ${ }^{42}$ as indicated in this paper as well. Prevalence of quit attempt was higher (prevalence ratio (PR) 2.32) among those who experienced tobaccorelated harm to their body or perceived that tobacco smoking can cause serious illness (PR: 2.121). Those who started smoking regularly after the age of 25 years had higher odds of quit attempts than those who started at the age of less than 15 years. Similar findings have been reported by previous studies as well. ${ }^{43}$ It is possible that a young adult, who started late, had comparatively more information on the ill effects of tobacco smoking. We found that the odds of quit attempts and intent to quit were higher among those who had experience of ill health due to tobacco smoking, or believed that tobacco smoking can cause serious illness. This may 
Table 3 Factors affecting intention to quit tobacco in future among the current smokers, GATS 2016-2017

\begin{tabular}{|c|c|c|c|}
\hline \multirow[b]{2}{*}{ Factor } & \multicolumn{3}{|c|}{ Intention to quit in future } \\
\hline & $\%(n=5382)$ & Unadjusted PR (95\% Cl) & Adjusted PR (95\% Cl) \\
\hline \multicolumn{4}{|l|}{ Age group } \\
\hline $15-24$ & 58.3 & 1.796 (1.793 to 1.799$)$ & 1.478 (1.474 to 1.482$)$ \\
\hline $25-44$ & 59.1 & 1.855 (1.852 to 1.857$)$ & 1.457 (1.455 to 1.459$)$ \\
\hline $45-64$ & 54.0 & 1.506 (1.504 to 1.508$)$ & 1.225 (1.224 to 1.227$)$ \\
\hline 65 and above & 43.8 & Ref & \\
\hline \multicolumn{4}{|l|}{ Sex } \\
\hline Male & 56.1 & 1.478 (1.476 to 1.480$)$ & 0.789 (0.787 to 0.790$)$ \\
\hline Female & 46.4 & Ref & \\
\hline \multicolumn{4}{|l|}{ Education } \\
\hline Graduation and above & 64.8 & 2.129 (2.124 to 2.133$)$ & 1.378 (1.374 to 1.381$)$ \\
\hline Up to secondary & 61.1 & $1.822(1.820$ to 1.823$)$ & 1.307 (1.305 to 1.309$)$ \\
\hline Up to primary & 58.3 & $1.617(1.615$ to 1.619$)$ & $1.304(1.302$ to 1.305$)$ \\
\hline No formal schooling & 46.3 & Ref & \\
\hline \multicolumn{4}{|l|}{ Occupation } \\
\hline Govt. and Non-govt. employee & 65.0 & 2.206 (2.202 to 2.209$)$ & 1.359 (1.356 to 1.362$)$ \\
\hline Student & 59.6 & 1.749 (1.744 to 1.755$)$ & 1.079 (1.073 to 1.084$)$ \\
\hline Daily wager & 55.8 & $1.498(1.496$ to 1.500$)$ & $1.276(1.274$ to 1.278$)$ \\
\hline Self employed & 55.3 & 1.469 (1.467 to 1.471$)$ & 1.225 (1.223 to 1.227$)$ \\
\hline $\begin{array}{l}\text { Retired/unemployed/ } \\
\text { homemaker }\end{array}$ & 45.7 & Ref & \\
\hline \multicolumn{4}{|l|}{ Caste } \\
\hline General & 58.5 & $1.328(1.326$ to 1.329$)$ & $1.146(1.145$ to 1.148$)$ \\
\hline Other backward class & 56.3 & 1.212 (1.211 to 1.213$)$ & 1.184 (1.182 to 1.185$)$ \\
\hline $\begin{array}{l}\text { Scheduled caste/scheduled } \\
\text { tribe }\end{array}$ & 51.5 & Ref & \\
\hline \multicolumn{4}{|l|}{ Marital status } \\
\hline Married & 56.1 & 1.800 (1.797 to 1.803$)$ & $1.227(1.225$ to 1.230$)$ \\
\hline Single & 55.5 & 1.751 (1.747 to 1.755$)$ & 0.901 (0.898 to 0.904$)$ \\
\hline Separated/divorced/widowed & 41.6 & Ref & \\
\hline \multicolumn{4}{|l|}{ Residence } \\
\hline Urban & 61.0 & $1.379(1.378$ to 1.380$)$ & 1.146 (1.144 to 1.147$)$ \\
\hline Rural & 53.2 & Ref & \\
\hline \multicolumn{4}{|l|}{ Smoking frequency } \\
\hline Less than daily smoking & 64.7 & $1.623(1.622$ to 1.625$)$ & 1.917 (1.913 to 1.921$)$ \\
\hline Daily smoking & 53.0 & Ref & \\
\hline \multicolumn{4}{|l|}{$\begin{array}{l}\text { Age of initiation of regular } \\
\text { smoking tobacco use }\end{array}$} \\
\hline$>25$ years & 55.1 & $1.152(1.150$ to 1.154$)$ & 1.159 (1.157 to 1.161$)$ \\
\hline 15-25years & 53.3 & $1.073(1.071$ to 1.075$)$ & 0.982 (0.981 to 0.984$)$ \\
\hline$<15$ years & 51.6 & Ref & \\
\hline \multicolumn{4}{|c|}{ Noticed information about the dangers of smoking tobacco or that encourages quitting } \\
\hline More than three sources & 63.0 & $2.193(2.190$ to 2.195$)$ & $1.562(1.560$ to 1.564$)$ \\
\hline Up to three sources & 56.2 & 1.656 (1.655 to 1.658$)$ & $1.380(1.379$ to 1.382$)$ \\
\hline Haven't noticed & 43.7 & Ref & \\
\hline
\end{tabular}


Table 3 Continued

\begin{tabular}{|c|c|c|c|}
\hline \multirow[b]{2}{*}{ Factor } & \multicolumn{3}{|c|}{ Intention to quit in future } \\
\hline & $\%(n=5382)$ & Unadjusted PR (95\% Cl) & Adjusted PR $(95 \% \mathrm{Cl})$ \\
\hline $\begin{array}{l}\text { Haven't seen any such } \\
\text { promotion }\end{array}$ & 55.5 & 1.067 (1.065 to 1.068$)$ & 1.309 (1.307 to 1.311$)$ \\
\hline $\begin{array}{l}\text { More than two sources } \\
\text { promoted tobacco smoking }\end{array}$ & 54.7 & 1.033 (1.031 to 1.034$)$ & 0.873 (0.871 to 0.874$)$ \\
\hline $\begin{array}{l}\text { Up to two sources promoted } \\
\text { tobacco smoking }\end{array}$ & 54.0 & Ref & \\
\hline \multicolumn{4}{|c|}{ Whether noticed any type of cigarette promotion } \\
\hline $\begin{array}{l}\text { One or other type of } \\
\text { promotion seen }\end{array}$ & 61.5 & 1.321 (1.319 to 1.323$)$ & 1.051 (1.049 to 1.053$)$ \\
\hline No promotion seen & 54.7 & Ref & \\
\hline \multicolumn{4}{|c|}{ Whether noticed any type of bidi promotion } \\
\hline $\begin{array}{l}\text { One or other type of } \\
\text { promotion seen }\end{array}$ & 57.5 & 1.107 (1.105 to 1.108$)$ & 1.144 (1.142 to 1.146$)$ \\
\hline No promotion seen & 55.0 & Ref & \\
\hline \multicolumn{4}{|c|}{ Has smoking already done harm to your body } \\
\hline Yes & 58.7 & 1.977 (1.972 to 1.982$)$ & 2.242 (2.235 to 2.249$)$ \\
\hline No & 52.5 & 1.535 (1.531 to 1.539$)$ & 1.863 (1.858 to 1.869$)$ \\
\hline Don’t know & 41.8 & Ref & \\
\hline \multicolumn{4}{|c|}{ Whether smoking tobacco causes serious illness } \\
\hline Yes & 56.5 & 4.378 (4.362 to 4.393$)$ & 2.924 (2.911 to 2.936$)$ \\
\hline No & 46.8 & 2.957 (2.946 to 2.968$)$ & 2.468 (2.457 to 2.479$)$ \\
\hline Don't know & 41.8 & Ref & \\
\hline \multicolumn{4}{|c|}{ Whether smoking tobacco causes no, one or multiple illnesses } \\
\hline$>3$ illnesses & 59.0 & 1.938 (1.934 to 1.942$)$ & 1.259 (1.256 to 1.263$)$ \\
\hline Up to 3 illnesses & 50.8 & 1.389 (1.386 to 1.392$)$ & 1.041 (1.038 to 1.043$)$ \\
\hline No illness & 42.6 & Ref & \\
\hline
\end{tabular}

GATS, Global Adult Tobacco Survey; PR, prevalence ratio.

include witnessing someone with declining health due to tobacco smoking.

Younger age, female sex and non-exposure to advertisements promoting smoking were common predictors of being in contemplation and preparation stages, as explained further. The possibility that societal norms against smoking are significantly stronger among these younger adult smokers, as seen by their high level of desire to quit. ${ }^{45}$ Women may have a higher risk of smokingrelated morbidity and mortality, and face different barriers to smoking cessation that warrant intervention. ${ }^{46}$ Women smokers are more likely to believe that society disapproves of smoking, perceive that the risk of dying from smoking significantly greater among them and have more concerns regarding health than men. ${ }^{47-49}$ Further, experience of ill health effects because of smoking was a common predictor to contemplation, preparation and relapse stage. The advancement to later stages in TTM model may be attributed to having experienced an illness due to smoking resulting in compromised health status, increased treatment costs and implied financial burden. ${ }^{50} 51$

This study has certain limitations. First, it is difficult to establish a temporal relationship between quit attempt/ intention to quit with other variables as it was secondary analysis of cross-sectional household survey. Second, the responses are also susceptible to recall bias. Further, as indicated in this paper, the odds of quit attempt were higher among those who experienced tobacco related harm to their body. It is possible that the majority of them were those who already had an episode of smoking-related illness. This theory was not, however, tested by the authors in the present paper due to lack of required information. The predictors of quit attempt and intention to quit may vary for various forms of tobacco consumption which was not included in this analysis. The age of first exposure to tobacco smoking, reasons for doing so and reasons for continuously indulging in tobacco smoking were not asked in GATS survey. Also, reasons for making quit attempts, if asked, could shed some light on potential motivational factors. 
Table 4 Multinomial logistic regression model to assess predictors of stages of change determining current tobacco smokers cessation behaviour, GATS 2016-2017

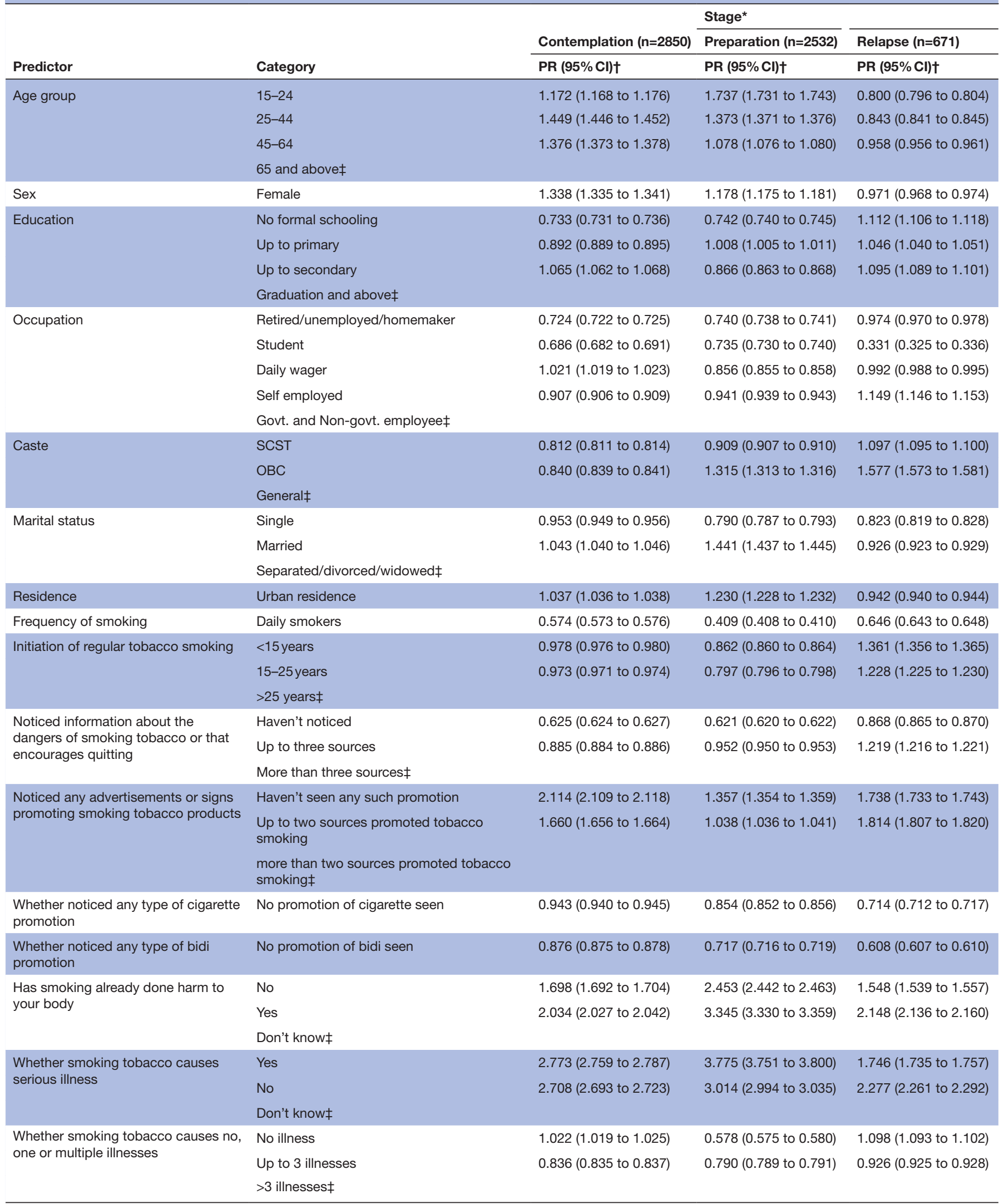

*Reference category: precontemplation stage.

†Adjusted.

†Redundant parameter.

GATS, Global Adult Tobacco Survey; OBC, Other backward class; PR, prevalence ratio; SCST, scheduled caste/scheduled tribe. 
We propose the following recommendations for policymakers, implementers, HCPs, researchers, academia and civil society advocates enhancing the quit attempts and promoting cessation among current smokers. Understanding the stage of behavioural change among these smokers could assist the stakeholders in developing such interventions that cater to the individual stages and facilitate the desired outcome. Dedicated cessation programmes addressing women and younger age groups could help the smoker's progress from contemplation to preparation and action stages. Checks on surrogate advertisements of tobacco products need to be strengthened along with steering of increased taxes on bidis to impact the affordability of the product. Further, concrete and aggressive mass media campaigns along with advertising mCessation and quitline services with wider coverage, especially for motivating smokers residing in rural areas, need to be implemented. Integrated capacity building initiatives on cessation for HCPs providing services under various national health programmes (noncommunicable disease control, oral health, maternal and child health, tuberculosis control, mental health, etc) may be introduced.

Further, building the motivation of HCPs to uptake and deliver cessation support (identification of smokers, sharing benefits, addressing barriers, coping strategies) is of paramount importance. Qualitative research must be conducted to understand the reasons for preferring not to make another quit attempt so that the causes of relapse can be addressed via individual counselling programmes. Also, research is necessary to understand the difference in cessation practices across different cross-cultural settings. Inclusion of smoking cessation as part of the medical curriculum that prioritises the need to ask about smoking habits and offer support to each user could be helpful. Civil society could mobilise community support for the uptake of cessation services and facilitate the exchange of good practices in cessation.

\section{Conclusion}

This study encapsulates and demonstrates that TTM approach is highly applicable in the current context. The factors influencing different stages of TTM were younger age, female sex, non-exposure to advertisements promoting smoking, for contemplation and preparation both. In addition, experience of ill health effects because of smoking was a common predictor to contemplation, preparation and relapse stage. This indicates that there is a need for designing stage-based cessation interventions at individual and population levels that caters and focuses on aforementioned groups and hard to engage groups such as older age groups. Given that experience of ill health effects because of smoking emerged to be a key predictor in later stages, it is essential to develop and implement intensive cessation treatment protocols in clinical settings utilising the flexibility of TTM model. Besides, India being an LMIC and a resource-constrained economy, it is vital to integrate cessation services into all possible national health programmes and policies to expand the outreach and the accessibility of cessation services. This could provide 'one stop solution' to many diseases, whether communicable or non-communicable, strengthening the health systems to support and achieve Sustainable Development Goals.

Contributors SG conceptualised the idea. GB did the review of literature. SG and KS designed the study. GB and RK performed the data curation. Data analysis was performed by RK. GB drafted the paper. The draft was critically revised for important intellectual content by all authors and thereafter approved the final version. All authors have read and approved the manuscript. SG is the guarantor for all aspects of the study ensuring those questions related to the accuracy or integrity of any part of the work that are investigated.

Funding The authors have not declared a specific grant for this research from any funding agency in the public, commercial or not-for-profit sectors.

Competing interests None declared.

Patient consent for publication Not applicable.

Ethics approval The ethical clearance was not sought as this work is on secondary data.

Provenance and peer review Not commissioned; externally peer reviewed.

Data availability statement Data are available in a public, open access repository. The dataset used for current analysis is available in a public repository from the Global Tobacco Surveillance System Data (GTSS Data) maintained by the Centers for Disease Control and Prevention.

Supplemental material This content has been supplied by the author(s). It has not been vetted by BMJ Publishing Group Limited (BMJ) and may not have been peer-reviewed. Any opinions or recommendations discussed are solely those of the author(s) and are not endorsed by BMJ. BMJ disclaims all liability and responsibility arising from any reliance placed on the content. Where the content includes any translated material, BMJ does not warrant the accuracy and reliability of the translations (including but not limited to local regulations, clinical guidelines, terminology, drug names and drug dosages), and is not responsible for any error and/or omissions arising from translation and adaptation or otherwise.

Open access This is an open access article distributed in accordance with the Creative Commons Attribution Non Commercial (CC BY-NC 4.0) license, which permits others to distribute, remix, adapt, build upon this work non-commercially, and license their derivative works on different terms, provided the original work is properly cited, appropriate credit is given, any changes made indicated, and the use is non-commercial. See: http://creativecommons.org/licenses/by-nc/4.0/.

\section{ORCID iDs}

Garima Bhatt http://orcid.org/0000-0002-5258-7339

Kathirvel Soundappan http://orcid.org/0000-0002-4839-0138

Rajbir Kaur http://orcid.org/0000-0002-2301-8647

\section{REFERENCES}

1 Office USPHS. Smoking cessation: a report of the surgeon general [online], 2020.

2 Taylor DH, Hasselblad V, Henley SJ, et al. Benefits of smoking cessation for longevity. Am J Public Health 2002;92:990-6.

3 Jha P. The hazards of smoking and the benefits of cessation: a critical summation of the epidemiological evidence in high-income countries. Elife 2020;9:e49979.

4 Office USPHS. Interventions for smoking cessation and treatments for nicotine dependence. Smoking cessation: a report of the surgeon general [online], 2020.

5 Chaiton M, Diemert L, Cohen JE, et al. Estimating the number of quit attempts it takes to quit smoking successfully in a longitudinal cohort of smokers. BMJ Open 2016;6:e011045.

6 Society AC. Guide to quitting smoking. Available: http://www.cancer. org/healthy/stayawayfromtobacco/guidetoquittingsmoking/guide-toquitting-smoking-pdf

7 Ellerman AFC, Stillman S. Smoking cessation: 7.7: personal factors associated with quitting. In: Scollo M, Winstanley M, eds. Tobacco in Australia: facts and issues. 52. 3rd edn. Carlton, VIC: Cancer Council Victoria, 2008. 
8 US Department of Health and Human Services, Public Health Women and smoking: a report of the surgeon general. Rockville, MD: US Department of Health and Human Services, Public Health, 2001.

9 Jiloha RC. Biological basis of tobacco addiction: implications for smoking-cessation treatment. Indian J Psychiatry 2010;52:301.

10 Prochaska JO, Velicer WF. The transtheoretical model of health behavior change. Am J Health Promot 1997;12:38-48.

11 Panda R, Venkatesan S, Persai D, et al. Factors determining intention to quit tobacco: exploring patient responses visiting public health facilities in India. Tob Induc Dis 2014:12:1-10.

12 Jung M. Exploring socio-contextual factors associated with male smoker's intention to quit smoking. BMC Public Health 2016;16:1-8.

13 Feng G, Jiang Y, Li Q, et al. Individual-level factors associated with intentions to quit smoking among adult smokers in six cities of China: findings from the ITC China survey. Tob Control 2010;19:i6-11.

14 Ministry of Health and Family Welfare Gol. Global adult tobacco survey: India report 2016-17, 2017.

15 World Health Organization. Who framework convention on tobacco control. who regional office for south-east Asia, 2004.

16 National Tobacco Control Cell MoH, Family Welfare Gol. Operational guidelines. National Tobacco Control Programme, 2015.

17 Panda R, Persai D, Venkatesan S. Missed opportunities for brief intervention in tobacco control in primary care: patients' perspectives from primary health care settings in India. BMC Health Serv Res 2015;15:1-9.

18 Kumar R, Saroj SK, Kumar M. Tobacco Quitline toll-free number on tobacco packets in India: an analysis on outcome. Monaldi Arch Chest Dis 2021:91.

19 Gopinathan P, Kaur J, Joshi S, et al. Self-reported quit rates and quit attempts among subscribers of a mobile text messaging-based tobacco cessation programme in India. BMJ Innov 2018;4:147-54.

20 Srivastava S, Malhotra S, Harries AD, et al. Correlates of tobacco quit attempts and cessation in the adult population of India: secondary analysis of the global adult tobacco survey, 2009-10. BMC Public Health 2013;13:1-8.

21 Coppo A, Baldissera S, Migliardi A, et al. Quit attempts and smoking cessation in Italian adults (25-64 years): factors associated with attempts and successes. Eur J Public Health 2017;27:717-22.

22 General USPHSOotS, Prevention NCfCD, Smoking HPOo. Preventing tobacco use among youth and young adults: a report of the surgeon general. US Government Printing Office, 2012.

23 Samim D, Méan M, Clair C, et al. A 10-year observational study on the trends and determinants of smoking status. PLoS One 2018;13:e0200010.

24 Pradhan PMS, Marahatta K. Cross-sectional survey on quitting attempts among adolescent smokers in Dharan, Eastern Nepal. $J$ Addict 2016:2016:1-5

25 Nargis N, Yong H-H, Driezen P, et al. Socioeconomic patterns of smoking cessation behavior in low and middle-income countries: emerging evidence from the global adult tobacco surveys and international tobacco control surveys. PLOS One 2019;14:e0220223.

26 Ozturk O, Mustafa U. Transtheoretic model in smoking cessation. J Exp Clin Med 2017;34.

27 Segan CJ, Borland R, Greenwood KM. Do transtheoretical model measures predict the transition from preparation to action in smoking cessation? Psychol Health 2002;17:417-35.

28 Chandramouli C, General R. Census of India 2011. Provisional Population Totals New Delhi, Government of India, 2011: 409-13.

29 National center for chronic disease prevention and health promotion, office of smoking and health, global tobacco surveillance system data (GTSSData).

30 Global Tobacco Surveillance System Collaborating Group. Global tobacco surveillance system (GTSS): purpose, production, and potential. J Sch Health 2005;75:15.
31 Liu KT, Kueh YC, Arifin WN, et al. Application of transtheoretical model on behavioral changes, and amount of physical activity among university's students. Front Psychol 2018;9:2402

$32 \mathrm{Han} \mathrm{H}$, Pettee Gabriel K, Kohl HW. Application of the transtheoretical model to sedentary behaviors and its association with physical activity status. PLoS One 2017;12:e0176330.

33 Nakabayashi J, Melo GR-isa, Toral N. Transtheoretical model-based nutritional interventions in adolescents: a systematic review. BMC Public Health 2020;20:1-14.

34 Nigg CR, Geller KS, Motl RW, et al. A research agenda to examine the efficacy and relevance of the transtheoretical model for physical activity behavior. Psychol Sport Exerc 2011;12:7-12.

35 Smith AL, Carter SM, Chapman S, et al. Why do smokers try to quit without medication or counselling? A qualitative study with exsmokers. BMJ Open 2015;5:e007301.

36 Mikkelsen SS, Dalum P, Skov-Ettrup LS, et al. What characterises smokers who quit without using help? A study of users and nonusers of cessation support among successful ex-smokers. Tob Control 2015;24:556-61.

37 Scotland A. Tobacco and older adults: a literature review. Edinburgh: ASH Scotland, 2004

38 Kerr $\mathrm{S}$, Watson $\mathrm{H}$, Tolson $\mathrm{D}$, et al. Smoking after the age of 65 years: a qualitative exploration of older current and former smokers' views on smoking, stopping smoking, and smoking cessation resources and services. Health Soc Care Community 2006;14:572-82.

39 Twigg L, Moon G, Szatkowski L, et al. Smoking cessation in England: intentionality, anticipated ease of quitting and advice provision. Soc Sci Med 2009;68:610-9.

40 Maguire CP, Ryan J, Kelly A, et al. Do patient age and medical condition influence medical advice to stop smoking? Age Ageing 2000;29:264-6.

41 Gilbert H, Sutton S, Sutherland G. Who calls quit? The characteristics of smokers seeking advice via a telephone helpline compared with smokers attending a clinic and those in the general population. Public Health 2005;119:933-9.

42 Jesus MCPde, Silva MHda, Cordeiro SM. [Understanding unsuccessful attempts to quit smoking: a social phenomenology approach]. Rev Esc Enferm USP 2016;50:71-8.

43 Khuder SA, Dayal HH, Mutgi AB. Age at smoking onset and its effect on smoking cessation. Addict Behav 1999;24:673-7.

44 Caponnetto P, Polosa R. Common predictors of smoking cessation in clinical practice. Respir Med 2008;102:1182-92.

45 Messer K, Trinidad DR, Al-Delaimy WK, et al. Smoking cessation rates in the United States: a comparison of young adult and older smokers. Am J Public Health 2008;98:317-22.

46 Allen AM, Oncken C, Hatsukami D. Women and smoking: the effect of gender on the epidemiology, health effects, and cessation of smoking. Curr Addict Rep 2014;1:53-60.

47 McKee SA, O'Malley SS, Salovey P, et al. Perceived risks and benefits of smoking cessation: gender-specific predictors of motivation and treatment outcome. Addict Behav 2005;30:423-35.

48 Chinwong D, Mookmanee N, Chongpornchai J, et al. A comparison of gender differences in smoking behaviors, intention to quit, and nicotine dependence among Thai university students. J Addict 2018;2018:1-8

49 Buckner JD, Vinci C. Smoking and social anxiety: the roles of gender and smoking motives. Addict Behav 2013;38:2388-91.

50 Hyland A, Li Q, Bauer JE, et al. Predictors of cessation in a cohort of current and former smokers followed over 13 years. Nicotine Tob Res 2004:6:363-9.

51 Daoud N, Hayek S, Sheikh Muhammad A, et al. Stages of change of the readiness to quit smoking among a random sample of minority Arab -male smokers in Israel. BMC Public Health 2015;15:1-13. 